\title{
CONHECIMENTO MASCULINO SOBRE MÉTODOS CONTRACEPTIVOS
}

\section{Men's Knowledge on contraceptive methods \\ Conocimiento masculino de métodos contraceptivos}

\section{RESUMO}

Objetivo: Analisar o conhecimento do gênero masculino frente aos métodos contraceptivos. Métodos: Pesquisa descritiva com delineamento qualitativo, desenvolvido em março de 2011, na Cidade de Queimadas (PB)-Brasil com 12 homens. A coleta de dados deu-se através de um formulário semiestruturado e foram submetidos à análise de conteúdo cujo produto originou categorias, ilustradas com as narrativas dos colaboradores: Conhecimento limitado sobre métodos anticoncepcionais; Participação masculina ditadora na anticoncepção. Resultados: Dessa forma, pode-se perceber que a visão masculina se processa diante de conhecimento limitado em relação à anticoncepção, que o gênero masculino ainda dita como a mulher deve se comportar diante da anticoncepção focando a responsabilidade apenas como feminina. Conclusão: Constatou-se que é necessário desconstruir preconceitos e permitir à população masculina a expressão de seus medos e anseios para que estes se sintam acolhidos nos serviços de saúde e passem a participar com maior ênfase no planejamento familiar.

Descritores: Enfermagem; Anticoncepção; Identidade de gênero; Saúde Sexual e Reprodutiva.

\section{ABSTRACT}

Objective: Analyze men's knowledge on contraceptive methods. Methods: Descriptive and qualitative research conducted in March 2011 in the city of Queimadas (PB)-Brazil with 12 men. Data were collected through a semi-structured form and underwent content analysis, which originated categories that were illustrated by the interviewee's reports: Limited knowledge on contraceptive methods; Men's participation ruling the contraception. Results: Thus, it was possible to notice that men's point of view is based on limited knowledge on contraception and they still rule how women should behave regarding contraception, taking it as a woman's responsibility. Conclusion: It was verified that there is a need to deconstruct prejudices and allow men to express their fears and desires so they can feel embraced by health services and start participating more in the family planning.

Descriptors: Nursing. Contraception. Gender identity. Sexual and Reproductive Health.

\section{RESUMEN}

Objetivo: Analizar el conocimiento del género masculino sobre los métodos contraceptivos. Métodos: Investigación descriptiva de delineamiento cualitativo desarrollado en marzo de 2011 en Queimadas (PB)-Brasil con 12 hombres. La recogida de datos se dio a través de un formulario semi-estructurado que fueron sometidos a análisis de contenido cuyo producto originó categorías ilustradas con las narrativas de los colaboradores: Conocimiento limitado de los métodos anticonceptivos; Participación masculina dictadora en la concepción. Resultados: De esa manera, se percibe que la visión masculina se procesa delante el conocimiento limitado respecto la anti concepción, que el género masculino todavía dicta como la mujer debe portarse delante la anticoncepción centrando la responsabilidad solamente como femenina. Conclusión: Se constató que es necesario eliminar prejuicios y permitir a la población masculina la expresión de sus miedos y ansias para que los mismos siéntanse acogidos en los servicios de salud y participen más fuertemente de la planificación familiar.

Descriptores: Enfermeria; Anticoncepción; Identidad de Género; Salud Sexual y Reproductiva.
Artigo Original

\author{
Maria Cidney da Silva Soares ${ }^{(1)}$ \\ Vanessa Carvalho Dourado de \\ Souza $^{(2)}$ \\ Pollyana Florêncio de Araújo \\ Costa $^{(1)}$ \\ Raimunda Mariana Oliveira de \\ Aquino Sarmento Paiva ${ }^{(1)}$ \\ Juliana Carvalho Andrade \\ Guerra $^{(1)}$ \\ Therezza Virgínia Vital Freire ${ }^{(1)}$
}

1) Faculdade de Ciências Médicas de Campina Grande - FCM - Campina Grande (PB) - Brasil

2) Hospital de Emergência e Trauma Dom Luiz Gonzaga Fernandes - Campina Grande (PB) - Brasil 


\section{INTRODUÇÃO}

Os arranjos familiares a partir do século XX sofreram mudanças, grande parte devido aos novos papéis assumidos pela mulher na sociedade. Havendo assim a valorização da família por parte das políticas sociais ${ }^{(1)}$. Observado a partir, dentre outras nuanças, da inserção das mulheres no mercado de trabalho que implicou em mudanças como a formação de famílias com proles reduzidas e também trouxe a orientação para o consumo de novas tecnologias reprodutivas, como a anticoncepção ${ }^{(2)}$.

Com a urbanização e a industrialização a maternidade tornou-se uma escolha reflexiva. $\mathrm{O}$ acesso das mulheres ao mercado de trabalho possibilitou a concepção diante da alternativa da contracepção. Era preciso romper com a ideia de que a maternidade era o determinante para justificar a posição da mulher na sociedade e na família, ultrapassar o biologismo e igualitar a responsabilidade entre homens e mulheres na escolha da concepção e contracepção ${ }^{(2)}$. Para o Ministério da Saúde, o Planejamento Familiar é um direito do cidadão e um dever do Estado, garantido pela Constituição Federal, através da Lei ${ }^{\circ} 9.263$ de 12 de janeiro de $1996^{(3)}$.

Com a criação do Programa de Assistência Integral à Saúde da Mulher (PAISM), em 1983, a questão da anticoncepção tornou-se uma preocupação das políticas de saúde ${ }^{(4)}$. Assim os programas de Planejamento Familiar vêm se preocupando predominantemente com a população feminina. Havendo a necessidade de priorizar a participação do casal ${ }^{(5)}$, que é uma das ações mais importantes na área da saúde.

Para isso, é preciso proporcionar aos casais informações e meios para que a decisão de ter ou não ter filhos seja livre. Em estudo efetivado em São Gonçalo do Amarante - CE - Brasil, em 2008, que analisou 171 prontuários sobre o uso dos métodos contraceptivos por mulheres dessa comunidade, apurou-se a baixa participação masculina, confirmando a maior responsabilidade feminina no controle reprodutivo $^{(6)}$.

Assim, o Ministério da Saúde lançou a Política Nacional de Atenção Integral à Saúde do Homem, no ano de 2009, e uma das suas metas seria aumentar a procura dos homens ao serviço de saúde em busca dos procedimentos urológicos e incentivar a sua participação na realização das consultas de pré-natal e planejamento familiar ${ }^{(7)}$. Para os profissionais de saúde, que estão em contato direto com pessoas em serviços básicos de saúde, ao lidar com a família como objeto de estudo é preciso desconstruir ideias já formadas em um biologismo, desvinculando-se de ideias próprias ${ }^{(1)}$, pois apesar de a fecundidade ser de interesse feminino, devido à gestação, é necessário incentivar e propiciar que os homens tenham acesso aos métodos contraceptivos.
A adesão masculina ao uso de métodos contraceptivos está relacionada com o grau de escolaridade destes. O pouco entendimento sobre os métodos contraceptivos é, na maioria das vezes, repassado pelos pais, amigos e irmãos, ocorrendo muitas vezes de modo distorcido e com informações erradas. Além de existirem poucos métodos voltados para esta população, o conhecimento destes limitase apenas para o preservativo masculino, coito interrompido e os utilizados por suas parceiras ${ }^{(5)}$.

Dessa forma, a ideia de que os homens, via de regra, não se interessam por questões relativas à sexualidade e à reprodução, e de que o planejamento familiar e o cuidado dos filhos são atribuições e responsabilidades das mulheres está embasada numa visão machista e sexista, que impede às mulheres e aos homens o pleno exercício de seus direitos sexuais e direitos reprodutivos, face às limitações impostas por padrões culturais inscritos em práticas preconceituosas ${ }^{(8)}$.

Percebe-se então a necessidade de maiores informações acerca do assunto para o gênero masculino, para que ocorra maior adesão aos métodos, assumindo assim a sua responsabilidade no planejamento familiar ${ }^{(5)}$.

Portanto, esta pesquisa intenta contribuir com as discussões em torno dessa temática buscando ampliar a visão de que a anticoncepção é uma realidade restrita à mulher, fazendo com que se perceba que a participação masculina se faz necessária, devendo ser um instrumento para que o casal tenha seus direitos sexuais e reprodutivos respeitados e que a prole seja uma opção livre e esclarecida. Por isso, investigar a participação do casal no Planejamento Familiar é importante para garantir a cidadania e que os serviços de saúde sejam um direito de todos.

Dessa forma, este estudo guiou-se a partir da seguinte questão norteadora: Qual o conhecimento do homem diante do planejamento familiar, especialmente sobre a anticoncepção? Diante do exposto, o objetivo deste estudo foi analisar o conhecimento do gênero masculino frente aos métodos contraceptivos.

\section{MÉTODOS}

Este estudo está contemplado dentro de uma abordagem qualitativa, "pois a interpretação tem muito que ver com a historicidade e a faticidade de qualquer conhecimento" (9). Trata-se de um estudo em que subjaz uma ideologia, pois, "ela veicula interesses e visões de mundo historicamente construidas e se submete e resiste aos limites dados pelos esquemas de dominação vigentes"(9)_ nesse caso, a ideologia de gênero.

O cenário para o desenvolvimento do estudo foi a Unidade Básica de Saúde da Família (UBASF) Central do município de Queimadas, localizado no interior do estado da Paraíba - Brasil. 
Fizeram parte desse estudo 12 homens escolhidos de forma aleatória não probabilística, sendo incluídos, os cadastrados na UBASF, que estavam na Unidade no período da coleta de dados, em março de 2011, sendo convidados a participar do estudo. Com o aceite, assinaram o Termo de Consentimento Livre e Esclarecido.

Para a coleta de dados foi aplicado um formulário semiestruturado, cuja primeira etapa, contemplou os dados de identificação, contendo as seguintes variáveis (idade, estado civil, escolaridade, profissão). A segunda etapa, continha questões relacionadas aos objetivos do estudo. Foram gravadas individualmente, com autorização previa dos entrevistados em local reservado, e posteriormente transcritas na íntegra, utilizando gravador MP3.

Para análise dos dados foi utilizada a técnica da análise de conteúdo ${ }^{(10)}$, pressupõe três etapas básicas: pré-análise, descrição analítica e interpretação inferencial. Essa técnica inclui dissociar os dados de suas fontes e das condições gerais que o produziram; colocar os dados num novo contexto, tendo como base dos objetivos e o objeto da investigação; recorrer a um sistema de conceitos analíticos cuja articulação permite formular as regras da inferência (10). Na pré-análise foi feita a organização do material, codificação, classificação e a categorização. Na etapa da interpretação inferencial foram estabelecidas relações com a realidade estudada, nessa fase obtém-se a partir do conteúdo manifesto o material necessário à interpretação inferencial apoiada nos dados, e no conteúdo latente, o desvelamento de ideologias ${ }^{(8)}$. Na busca pela compreensão foi feita a leitura atenta dos doze depoimentos, buscando apreender nas suas falas o significado deste experienciar. É por meio da fala, do dizer de cada um sobre a experiência, que o fenômeno se mostra. Assim, as categorias selecionadas para análise foram as seguintes: Conhecimento limitado do homem em relação à anticoncepção e Participação masculina ditadora na anticoncepção.

O projeto seguiu as normas da Resolução 466/12, do Conselho Nacional de Saúde, que dispõe sobre a realização de pesquisa com seres humanos ${ }^{(11)}$, sob a aprovação do Comitê de Ética e Pesquisa, do Centro de Ensino Superior e Desenvolvimento, protocolado sob o número 6824.0.000.405-11. Para manter o anonimato os entrevistados (E) foram enumerados, para não serem identificados (I - II - III...).

\section{RESULTADOS E DISCUSSÃO}

A seguir, a apresentação dos dados de identificação dos colaboradores do estudo e as categorias temáticas:

\section{Caracterização dos dados de identificação dos entrevistados}

Em relação ao estado civil dos participantes sete são casados, dois separados, três solteiros, destes solteiros dois relataram que tiveram união estável anteriormente. A faixa etária mínima foi 18 anos e a máxima 63 anos, houve predomínio da faixa etária dos 30 aos 50 anos. Quanto à escolaridade nove possuem o ensino médio incompleto, dois o ensino médio completo e um considera-se alfabetizado. As profissões de agricultor e porteiro foram as mais citadas e a cor branca a predominante. Dos 12 participantes somente um não possui filhos, mas está planejando tê-lo.

\section{Conhecimento masculino limitado em relação à anticoncepção}

A categoria conhecimento masculino limitado em relação à anticoncepção, evidencia que os entrevistados não conhecem sobre os métodos contraceptivos. Dos quais, os mais citados são a camisinha e a pílula, como pode ser visto pelas falas a seguir:

"[...] em parte comprimido [...] no momento nenhum, por que a mulher que tomou, minha esposa tomou a muito que até me esqueci agora com essa idade né? Ai não sei." $(E-I)$.

"só comprimido né?" (E-III).

"métodos é? Camisinha né? no caso da mulher tem os comprimidos né anticoncepcional." (E-IV).

A participação masculina no planejamento reprodutivo é um dever e também um direito, não somente como uma obrigação legal, mas de participar de todo o processo de ter ou não ter filhos, disponibilizando informações e métodos contraceptivos para que a paternidade seja vivenciada de forma responsável ${ }^{(12)}$.

Um estudo realizado com homens de 25 a 29 anos, aponta que o conhecimento masculino acerca dos métodos contraceptivos está na maioria das vezes associado à alta incidência de parceiras que não se adaptaram às pílulas hormonais, fazendo com que ambos procurassem métodos alternativos, facilitando assim o caminho para que as ações do planejamento familiar alcancem seus objetivos ${ }^{(13)}$, como também conhecer as características culturais de cada comunidade e assim programar as ações que contemplem as singularidades dos casais.

O Ministério da Saúde ${ }^{(14)}$ disponibiliza nove métodos anticoncepcionais nas unidades de saúde: anticoncepcional injetável trimestral, anticoncepcional injetável mensal, pílula oral combinada, diafragma, DIU, preservativo masculino, preservativo feminino, pílula de emergência e a minipílula. Porém os homens desse estudo desconhecem esses métodos, provavelmente por conta de seu pouco entrosamento nos serviços de saúde. Apesar de os homens terem responsabilidade na escolha de qual método deverá ser usado pelo casal, existem poucos dados referentes à atitude masculina frente à anticoncepção ${ }^{(15)}$. 
Quando o entrevistado III disse" só comprimido né?.", reflete o desconhecimento do sobre outros métodos contraceptivos, no qual se pode associar a cultura existente de que a mulher é a responsável pela reprodução e assim destinando a ela toda a responsabilidade de ter ou não ter filhos. Em relação à situação conjugal esta se baseia sob a influência das relações de gênero, e na primeira a cultura "machista" e a política autoritária impõem sobre a mulher e seu corpo o uso de métodos contraceptivos e controle da fecundidade ${ }^{(16)}$.

$\mathrm{Na}$ fala do entrevistado a seguir fica evidente que apesar de conhecer como métodos contraceptivos a camisinha e a vasectomia, a vasectomia sendo citado ainda de forma interrogativa, deixa claro que é a mulher a responsável pelo uso do contraceptivo na relação.

"a pílula que a mulher usava, usa. Essa camisinha. A que eu conheço mesmo é a operação que o homem faz, como é que chama mesmo que faz? Vasectomia né? Eu só conheço esse três." (E-VI).

O desconhecimento masculino reflete diretamente na responsabilidade da mulher no Planejamento Familiar, é ela quem usa e assim é a responsável direta pelo controle de natalidade. Por outro lado, é direito também dos homens terem informação e autonomia nas decisões do casal. Mas, discutir essa autonomia remete também a uma cultura em que a mulher, desde a criação de políticas que visavam o controle da fecundidade, era a responsável pela reprodução. $\mathrm{O}$ relato do entrevistado expõe isto:

\section{"Ohh!! [...] eu não conheço nem um não." (E-V).}

Por essa expressão, pode se questionar se as ações voltadas para a promoção da saúde estão sendo realizadas como forma de prevenção aos agravos à saúde e de qualidade de vida. Não conhecer nenhum método contraceptivo leva ainda a questionar uma eventual paternidade e maternidade não desejada ou que as ações de promoção e prevenção em saúde estão focadas quase que exclusivamente nas mulheres, o que reflete em um baixo impacto dessas ações, sendo o homem apenas visto como o causador do problema e não como sujeito necessário para a solução(17).

Assim o homem poderá ser visto também como sujeito parte de uma relação, e que ele também poderá ser o responsável pela escolha do método contraceptivo que garantirá sua autonomia, essa não direcionada por um biologismo, mas para a igualitária responsabilidade. Em outra fala ouviu-se:

"rapaz eu conheço a camisinha assim tal. A camisinha... pra mulher o DIU né, aquela camisinha também que ela usa se eu não me engano, comprimido assim, no tempo que en era casado ela num usou sabe e nem eu a camisinha né. Primeiro que eu sou cristão sabe e não tem assim, não uso método, mais assim formal, procuro mais assim viver o natura." (E-VII).

Ressalta-se nesta fala a religião como norteadora da formação da família. É de responsabilidade do casal a decisão de ter filhos ou não, baseando-se nas condições econômicas e da estabilidade do $\operatorname{lar}^{(18)}$, cabe ao estado o dever de informar e de orientar e não de impor, respeitando as crenças e convicções religiosas, discute-se aqui não os princípios cristãos, mas até onde esses princípios direcionam a vivência de uma reprodução sem nenhum controle de natalidade. O entrevistado XI relatou:

"pra que a mulher toma, né? eu esqueço o nome do remédio, que ela tomou faz uns 8 anos que ela não bebe isso, mas também ela não pode ter mais filho né, que ela ta seca a uns dois anos, ela tomou mais ou menos durante uns dois anos só. Era comprimido né aquele que toma, como é o nome que dá? É que esqueço né. Eu nunca tomei. Mas seu eu for sair com uma mulher estranha eu uso camisinha, eu uso sim." (E-XI).

"como assim comprimido? Não [...] não!!! Sim às vezes eu uso a camisinha eu uso camisinha, não é todo dia que eu uso. Eu não gosto da camisinha né, eu posso te responder isso né? (risos)." (E-XI).

Nota-se, por esse relato, que mesmo conhecedor de que a camisinha é um método contraceptivo, não é usado em sua relação conjugal. No Brasil está havendo uma mudança da atitude masculina em relação à contracepção, mas não se sabe se essa mudança refere-se ao fato de proteger-se de doenças sexualmente transmissíveis ou devido à uma mudança nas relações de gênero ${ }^{(13)}$.

Verificou-se pouca aceitabilidade dos homens em utilizar o preservativo, principalmente aqueles que vivenciam uma união estável, devido à associação entre o referido método com a prevenção de Infecções Sexualmente Transmissíveis (IST), as quais estão vinculadas a práticas sexuais consideradas de risco, e não como mais uma opção de método contraceptivo ${ }^{(5)}$. Em outro estudo ${ }^{(19)}$ com homens que viviam no oeste de Santa Catarina em 2005, os autores afirmam que o uso do preservativo fora do casamento tem a função de evitar a gravidez e o contágio por doenças que acabariam denunciando a relação extraconjugal. Porém, o uso do preservativo na maioria dos casos está presente nos primeiros encontros, mas depois é dispensado, ou por conhecer a história sexual da parceira, ou por delegar a ela o uso do preservativo oral. No mesmo estudo verifica-se que quando questionados quanto ao uso do preservativo masculino nas relações conjugais eles relacionam o uso da camisinha com suas parceiras como um símbolo de infidelidade e de falta de confiança. 
Aqui nota-se que o homem, apesar de preocupar-se com seu casamento, esta preocupação limita-se a não ser julgado como traidor. Preocupa-se em usar a camisinha com outras mulheres fora de sua relação estável, mas julga como obrigação da sua esposa o uso do contraceptivo. A relação extraconjugal aqui não é o objeto de estudo. Pretende-se analisar e discutir a relação homem-mulher e como o método contraceptivo é usado na relação. Assim percebe-se que, mesmo nas relações fora do casamento, há a subordinação da mulher quanto ao uso do contraceptivo. Destaca-se a seguinte fala:

"foi, todos os dois, mas tive dois fora do casamento que não foram (risos), eu confiei que ela tinha tomado comprimido." (E-XI).

Enfatiza-se também que o uso da camisinha garante dupla proteção, pois além de evitar uma gravidez não planejada também protege o indivíduo contra as IST, porém tais benefícios muitas vezes não são considerados, por questões culturais, em pessoas que possuem uma união estável, aumentando a incidência de mulheres infectadas pelo HIV, IST e gestações indesejadas ${ }^{(5)}$. Quando há participação masculina no Planejamento Familiar, percebese que essa é ditada pelo homem para a mulher, fazendo com que a responsabilidade seja da mulher e não do homem na idealização da prole, é o que se pode perceber na próxima categoria.

\section{Participação masculina ditadora na anticoncepção}

Para trabalhar essa categoria, destaca-se esse relato:

"não, nunca conversei, isso é da minha parte, eu faço minha parte e ela faz a dela, procurar se informar também." (E-VIII. Grifo Nosso).

O feminismo surgiu para combater um dos pilares da dominação masculina, que é a dependência da sexualidade com a reprodução e todos os seus efeitos na vida social, familiar e política ${ }^{(2)}$. Rompendo não só com a subordinação em relação à contracepção, mas também para desvincular o determinismo biológico, tornando a maternidade uma escolha livre para as mulheres.

Apesar da necessidade e esforços para igualitar direitos e deveres entres os sexos, ou seja, deixar o biologismo e encarar as relações sem subordinação, o ideário masculino ainda reflete a divisão de tarefas entre homens e mulheres, onde a cada um cabe um papel, que historicamente a mulher reproduz. Mesmo na tentativa de busca de saberes "eu faço a minha parte" esses conhecimentos não são para igualitar, mas para reforçar a desigualdade já existente.

Uma definição, para a década atual, de Planejamento Familiar, não pode deixar de ser democrática, que leve em consideração a liberdade do casal em decidir o número de filhos que podem ou querem ter. Mais ainda, que seja realizada com a consciência de gênero, no sentido de se incluir o homem nas atividades e no Programa de Planejamento Familiar e compreender a posição da mulher na sociedade, bem como procurar identificar a ideologia que permeia o Planejamento Familiar, contribuindo com a explanação dos direitos de cidadãos que devem exercer tanto o homem quanto a mulher ${ }^{(20)}$.

Outro fator importante é a necessidade de expansão nos serviços de saúde sobre a saúde do homem, tendo em vista que a maioria dos serviços não disponibiliza sistemática para atender a população masculina. Destaca-se a seguinte fala:

“me sinto responsável. Até hoje eu sou responsável, tem dois maior de idade e a outra tem 19, quer dizer, os três são maiores, os três tão dentro de casa ainda." (E-10).

A responsabilidade aqui é vista como a obrigação de suprir financeiramente a família, sendo assim, a participação masculina no planejamento familiar acontece quando há uma preocupação financeira para cuidar da família, em que culturalmente ele é provedor da casa ${ }^{(5)}$. A escolha do método contraceptivo pela mulher deve ser baseada na liberdade de escolha e no direito à informação, para o autor é neste momento que o homem deve ser incentivado a estar com sua parceira e também ter acesso à informação e conhecer sobre esses métodos. Na fala do entrevistado X:

"hoje em dia não conversa mais não né, não tem mais necessidade. Mas antes conversava. Sobre a criação de dá os filhos, sobre evitar, essas coisas. Aí quando ela não pôde tomar mais comprimido eu conversei com o médico né, falando sério, eu não gostava de usar a camisinha né, ai ele disse: faz assim, vocês têm mais esse e depois a gente faz a ligação dela, por que ela não pode tomar comprimido mais, por que ela tem problema, ai o medico chegou e disse: você não pode ter mais filho, vai ter esse ai." (E-X. Grifo Nosso).

Nesta fala, as relações de responsabilidade estão embasadas na subordinação da mulher, e a seu corpo a contracepção "quando ela não pôde tomar mais o comprimido (...) e depois a gente faz a ligação dela". A figura masculina não aparece como sujeito também capaz de praticar a contracepção, mas de apoiar a mulher na prática da esterilização. $\mathrm{E}$ isso acontece pela forte influência do homem frente ao planejamento familiar, já que estes mantêm o controle sobre o lar através das atribuições femininas como cuidadoras, e por eles serem os provedores da família. O que influencia o mesmo gênero a ser mais ausente nos métodos de contracepção, fazendo, assim, cair toda responsabilidade para suas parceiras ${ }^{(21)}$. 
A opção pela reprodução deve ser uma atitude responsável e consciente e, ainda, partilhada pelo casal. A realidade socioeconômica sugere famílias de pequeno porte, mais adequadas ao orçamento familiar e às atividades da mulher e do homem no mercado de trabalho ${ }^{(20)}$.

Portanto, o compromisso profissional para com o atendimento da clientela é um dever profissional, discutindo seus direitos aos serviços públicos, como os oferecidos pelo Planejamento Familiar com a participação do casal.

\section{CONSIDERAÇÕES FINAIS}

Com esse estudo, constatou-se que os homens têm uma participação mínima na escolha e uso dos métodos contraceptivos nas suas relações. A subordinação da mulher identificada neste estudo é resultado de uma desigualdade de gênero historicamente construída. A mulher é vista como o sexo responsável pela reprodução, o homem como sexo instintivo que deve ser capaz de ser o provedor da família. Apesar das Políticas Públicas existirem para orientar e executar ações que promovam o bem-estar e legitimar os direitos dos cidadãos e cidadãs, elas se mostram ausentes ou ineficazes. O Planejamento Familiar é um direito Constitucional, é direcionado para que a maternidade e paternidade sejam vivenciadas de forma responsável e deve ser respeitada.

É imperativo reconhecer que a saúde sexual e reprodutiva não se restringem à oferta de métodos contraceptivos, visam também assegurar que os casais tenham a liberdade de escolha de ter ou não ter filhos através do acesso à informação. Não se pode legitimar a autonomia e a igualdade entre os gêneros sem se conhecer as singularidades existentes entre homens e mulheres, elas não são excludentes, devem ser o ponto norteador para que as Políticas Públicas sejam uma realidade.

\section{AGRADECIMENTOS}

Os agradecimentos desse trabalho são especialmente aos homens cadastrados na Unidade Básica de saúde e que participaram desse estudo.

\section{REFERÊNCIAS}

1. Ohara ECC, Saito RXS. Saúde da família: considerações teóricas e aplicabilidade. São Paulo: Martinari; 2013.

2. Scavone L. Religiões, gênero e feminismo. Rev Estudos da Religião, 2008; 2(4): 1-8. Disponível em: http://www.pucsp.br/rever/rv4_2008/t_scavone.htm

3. Brasil. Congresso Nacional. Lei ${ }^{\circ}$ 9.263, de 12 de Janeiro de 1996 [acesso em 2014 Nov 11]. Disponível em: http://www.planalto.gov.br/ccivil_03/leis/19263. htm

4. Costa NFP, Almeida M. Normas técnicas em anticoncepção. $2^{\mathrm{a}}$ ed.Rio de Janeiro: Bemfam; 2007.

5. Brito RS, Santos DLA. Contextualizando o homem no planejamento familiar: um estudo bibliográfico. Rev Pesqui Cuid Fundam (Online). 2011;3(1):1720-28.

6. Teles LMR, Silva SS, Eduardo KGT, Moura ERF, Damasceno AKC. Atenção em anticoncepção oferecida por equipe de PSF em São Gonçalo do Amarante - CE. Rev Eletronica Enferm. 2010;12(4):711-8.

7. Ministério da Saúde (BR). MS lança Política Nacional de Saúde do Homem. Brasília: Ministério da Saúde; 2009.

8. Ghanem E, organizador. Influir em políticas públicas e provocar mudanças sociais: experiências a partir da sociedade civil brasileira. São Paulo: Imprensa Oficial do Estado de São Paulo; 2007.

9. Minayo MCS. O desafio do conhecimento: pesquisa qualitativa em saúde. $14^{\mathrm{a}}$ ed. São Paulo: HUCITEC; 2014.

10. Bardin L. Análise de conteúdo. $3^{\mathrm{a}}$ ed. Lisboa: Edições $70 ; 2006$.

11. Ministério da Saúde (BR), Conselho Nacional de Ética em Pesquisa. Normas para Pesquisa envolvendo seres humanos: Resolução CNS 466/12 e outras [internet]. Brasília: Ministério da Saúde; 2012 [acesso em 2014 Nov 10]. Disponível em: http://conselho.saude.gov.br/ resolucoes/2012/Reso466.pdf

12. Ministério da Saúde (BR), Planejamento familiar. Brasília: Ministério da Saúde; 2010.

13. Oliveira MC, Bilac ED, Muszkat M. As novidades do gênero: homens e anticoncepção em camadas médias. In: Quadros MT, Lewis L. Homens e dinâmicas culturais: saúde reprodutiva, relações raciais, violência [internet]. Recife: Editora Universitária da UFPE; 2011 [acesso em 2014 Nov 10]. (Família e gênero, $\left.n^{\circ} 13\right)$. Disponível em: http:/www.ufpe.br/fagesufpe/ images/documentos/Livros_Fages/homens $\% 20 \mathrm{e} \% 20$ dinmicas $\% 20$ culturais $\% 20$ sade $\% 20$ reprodutiva $\% 20$ rela_es\%20raciais\%20violncia.pdf

14. Ministério da Saúde (BR). Linha do tempo dos objetivos de desenvolvimento do milênio. Brasilia: Ministério da Saúde; 2011.

15. Duarte GA. Perspectiva masculina quanto a métodos contraceptivos. Cad Saúde Pública [periódico na internet]. 1998 [acesso em 2014 Nov 10];1(14):125- 
30. Disponível em: http://www.scielo.br/scielo. php?pid=S0102-311X1998000500022\&script $=$ sci arttext

16. Pirrota KCM, Schor N. A mulher e a esterilização: a trajetória rumo a laqueadura tubária. XI Encontro Nacional de Estudos populacionais da ABEP. Caxambu, 1998. p. 121-49.

17. Silva VLQ. Sexualidade masculina e saúde do homem na Estratégia de Saúde da Familia: trabalhando com a equipe com a pesquisa-ação [dissertação]. Ribeirão Preto: Escola de Enfermagem de Ribeirão Preto/USP; 2009 [acesso em 2014 Nov 10]. Disponível em: http:// www.teses.usp.br/teses/disponiveis/22/22131/tde26042010-101720/pt-br.php

18. Gelain I. A ética, a bioética e os profissionais de enfermagem. $4^{\mathrm{a}}$ ed. São Paulo: Editora Pedagógica e Universitária; 2010.

19. Madureira V, Trenenti M. Da utilização do preservativo masculino à prevenção de DST/AIDS. Ciênc Saúde Coletiva. 2008;13(6):1807-16.

20. Sauthier M, Barbosa MLG. Gênero e planejamento familiar: uma abordagem ética sobre o compromisso profissional pará uma integração do homem. Rev
Bras Enferm [periódico na internet]. 2011 [acesso em 2014 Nov 10]64(3):457-64. Disponível em: http://www.scielo.br/scielo.php?pid=S0034$71672011000300008 \&$ script $=$ sci arttext

21. Quadros MT. Homens, valores e práticas relacionadas à contracepção em grupos populares. In: Quadros MT, Lewis L. Homens e dinâmicas culturais: saúde reprodutiva, relações raciais, violência [internet]. Recife: Editora Universitária da UFPE; 2011 [acesso em 2014 Nov 10]. (Família e gênero $\mathrm{n}^{\mathrm{o}}$ 13). Disponível em: http://www.ufpe.br/fagesufpe/ images/documentos/Livros_Fages/homens $\% 20 \mathrm{e} \% 20$ dinmicas $\% 20$ culturais $\% 20$ sade $\% 20$ reprodutiva $\% 20$ rela_es $\% 20$ raciais $\% 20$ violncia.pdf

\section{Endereço de correspondência:}

Maria Cidney da Silva Soares

Faculdade de Ciências Médicas/Centro Superior de Ensino e Desenvolvimento

Avenida Senador Argemiro de Figueiredo, 1901

Bairro: Itararé

CEP: 581411-020 - Campina Grande - PB - Brasil 